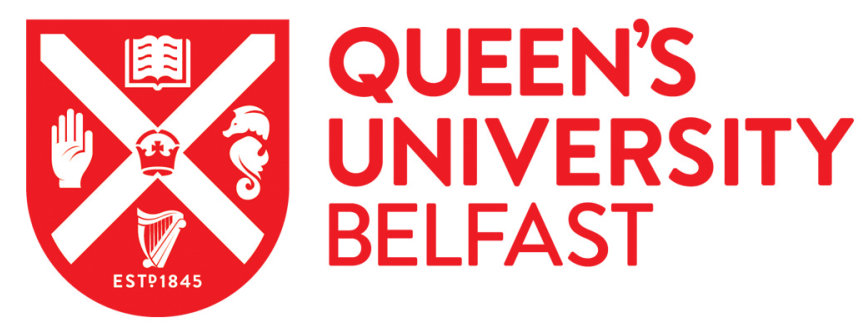

\title{
Resting energy expenditure in non-ventilated, non-sedated patients recovering from serious traumatic brain injury: Comparison of prediction equations with indirect calorimetry values
}

McEvoy, C. T., Cran, G. W., Cooke, S. R., \& Young, I. S. (2009). Resting energy expenditure in non-ventilated, non-sedated patients recovering from serious traumatic brain injury: Comparison of prediction equations with indirect calorimetry values. Clinical Nutrition, 28(5), 526-532. https://doi.org/10.1016/j.clnu.2009.04.009

Published in:

Clinical Nutrition

Queen's University Belfast - Research Portal:

Link to publication record in Queen's University Belfast Research Portal

\section{General rights}

Copyright for the publications made accessible via the Queen's University Belfast Research Portal is retained by the author(s) and / or other copyright owners and it is a condition of accessing these publications that users recognise and abide by the legal requirements associated with these rights.

Take down policy

The Research Portal is Queen's institutional repository that provides access to Queen's research output. Every effort has been made to ensure that content in the Research Portal does not infringe any person's rights, or applicable UK laws. If you discover content in the

Research Portal that you believe breaches copyright or violates any law, please contact openaccess@qub.ac.uk. 
Original Article

\title{
Resting energy expenditure in non-ventilated, non-sedated patients recovering from serious traumatic brain injury: Comparison of prediction equations with indirect calorimetry values
}

\author{
Claire T. McEvoy ${ }^{\mathrm{a}, *}$, Gordon W. Cran ${ }^{\mathrm{a}}$, Stephen R. Cooke ${ }^{\mathrm{b}}$, Ian S. Young ${ }^{\mathrm{a}}$ \\ ${ }^{a}$ Centre for Public Health, Queens University Belfast, BT12 6BJ, Northern Ireland, UK \\ ${ }^{\mathrm{b}}$ Regional Neurosurgery Unit, Belfast Health E Social Care Trust, Royal Victoria Hospital Belfast, BT12 6BA, Northern Ireland, UK
}

\section{A R T I C L E I N F O}

\section{Article history:}

Received 28 October 2008

Accepted 1 April 2009

\section{Keywords:}

Brain injury

Energy expenditure

Indirect calorimetry

\begin{abstract}
S U M M A R Y
Background \& aims: Little is known about energy requirements in brain injured (TBI) patients, despite evidence suggesting adequate nutritional support can improve clinical outcomes. The study aim was to compare predicted energy requirements with measured resting energy expenditure (REE) values, in patients recovering from TBI.

Methods: Indirect calorimetry (IC) was used to measure REE in 45 patients with TBI. Predicted energy requirements were determined using $\mathrm{FAO} / \mathrm{WHO} / \mathrm{UNU}$ and Harris-Benedict (HB) equations. BlandAltman and regression analysis were used for analysis.

Results: One-hundred and sixty-seven successful measurements were recorded in patients with TBI. At an individual level, both equations predicted REE poorly. The mean of the differences of standardised areas of measured REE and $\mathrm{FAO} / \mathrm{WHO} / \mathrm{UNU}$ was near zero $(-9 \mathrm{kcal}$ ) but the variation in both directions was substantial (range -591 to $+573 \mathrm{kcal}$ ). Similarly, the differences of areas of measured REE and HB demonstrated a mean of $1.9 \mathrm{kcal}$ and range -568 to $+571 \mathrm{kcal}$. Glasgow coma score, patient status, weight and body temperature were significant predictors of measured REE $\left(p<0.001 ; R^{2}=0.47\right)$.

Conclusions: Clinical equations are poor predictors of measured REE in patients with TBI. The variability in REE is substantial. Clinicians should be aware of the limitations of prediction equations when estimating energy requirements in TBI patients.
\end{abstract}

Crown Copyright @ 2009 Elsevier Ltd and European Society for Clinical Nutrition and Metabolism. All rights reserved.

\section{Introduction}

Patients sustaining a serious moderate to severe traumatic brain injury (TBI) often require long periods of hospitalisation involving intensive care and rehabilitation.

Severe metabolic disturbances have been observed in patients sustaining a serious TBI. The systemic effects of the metabolic response to head injury include: increased energy demands; increased protein turnover; a hyperdynamic cardiovascular state; impaired glucose metabolism; altered mineral and trace element status; increased cytokine and hormonal release and altered gastrointestinal function. The systemic effects of this metabolic response, if they remain unchecked, can increase the risk of

\footnotetext{
* Corresponding author. Centre for Public Health, Department of Medicine, Lower Ground Floor, Pathology Building, Queens University Belfast, Grosvenor Road, Belfast, BT12 6BJ, Northern Ireland, UK. Tel.: +44 02890972557; fax: +44 02890235900

E-mail address: c.mcevoy@qub.ac.uk (C.T. McEvoy).
}

secondary complications in patients with TBI and ultimately increase mortality.

Nutritional intervention can play an important role in reducing the risk of developing secondary complications. A review by the Cochrane Collaboration concluded that early nutritional support may be associated with a trend towards better outcomes in terms of survival and disability in this patient group. ${ }^{1}$ More recent work demonstrated that patients who were not fed within 5 and 7 days after TBI had a two- and four-fold increased likelihood of death. ${ }^{2}$ However, the provision of adequate nutritional support to meet individual energy demands is often challenging in practice. This is largely due to the uncertainty regarding actual energy requirements in this clinical group.

Traditionally in clinical practice, energy requirements are calculated using prediction equations, validated for use mainly in healthy populations. A stress or injury factor is often applied depending on the estimated degree of metabolic response to injury. A further factor may be applied to encompass physical activity level 
and diet induced thermogenesis to provide an overall estimate of total energy requirements.

In patients with brain injury, there is considerable variability in measured REE in the first 2 weeks of injury, with some patients yielding measured REE at near normal values and some patients demonstrating extreme hypermetabolism, up to $100 \%$ above normal calculated values. ${ }^{3-5}$ The reported variability has been attributed to the effects of sedation, barbiturate therapy, steroid treatment, mechanical ventilation, diet induced thermogenesis and/or infection. Patients receiving sedatives and or muscle relaxants were found to have a mean measured REE 30\% lower than those patients not receiving sedation or in barbiturate coma. ${ }^{6-8}$ Current guidelines for nutrition in TBI recommend replacing $140 \%$ of the REE in non-paralyzed patients and $100 \%$ in paralyzed patients by the seventh day of injury. ${ }^{9}$

Research to date provides little information regarding REE in head injured patients after 2 weeks, typically when ventilation and sedation has been stopped and patients are in various degrees of consciousness and breathing spontaneously. There is also little information regarding the factors determining energy requirements in the later stages of trauma in this complex patient group.

The main aim of this study was to compare predicted REE values, using the equations of Harris-Benedict and FAO/WHO/UNU in a group of non-sedated, non-ventilated patients recovering from TBI, with indirect calorimetry values using the methods comparison analysis described by Bland and Altman. ${ }^{10}$ A second aim of this study was to determine factors that can predict REE in this patient group.

\section{Materials and methods}

Forty-five patients with an isolated traumatic brain injury (TBI), were recruited from the Regional Neurosurgical Unit at The Royal Group of Hospitals, Belfast, between January 2005 and June 2006. All patients were breathing spontaneously and were not receiving sedation. The study was given ethical approval from the NHS Research Ethics Committee, Northern Ireland. Informed consent was provided by the patients' next of kin.

\subsection{Subjects}

All patients had a glasgow coma score $($ GCS $) \leq 11$ on admission and were severely brain injured but were not pronounced brain dead. They were haemodynamically stable without clinically significant additional trauma other than the brain injury. All patients were receiving $\leq 40 \%$ supplementary oxygen and were not sedated or artificially ventilated.

\subsection{Measurements}

Each patient underwent repeated daily measurements of resting energy expenditure (REE) and nutrition assessment for approximately 7-9 days after sedation and artificial ventilation were stopped. All metabolic and nutritional assessments were conducted by the same observer between 10.00 and $14.00 \mathrm{~h}$ in a ward environment with an ambient temperature of $25^{\circ} \mathrm{C}$. The patient lay in a recumbent position following a 4-h fast and with no nursing, medical or therapist intervention for $1 \mathrm{~h}$ prior to the measurement time. Weight was measured using hoist scales (opera hoist scales, Argo ltd, Gloucester.UK) at least $1 \mathrm{~h}$ prior to the measurement time and recorded to the nearest $0.1 \mathrm{~kg}$. Length was measured with a tape measure while the patient was in the recumbent position without footwear. Length was recorded to the nearest centimetre. Body mass index (BMI) $\left(\mathrm{kg} / \mathrm{m}^{2}\right)$ was calculated as weight $(\mathrm{kg}) /$ height $^{2}(\mathrm{~m})$. Clinical information including demographics diagnosis, surgical intervention, days since injury, drug treatments, body temperature $\left({ }^{\circ} \mathrm{C}\right), \mathrm{GCS}$, concentration of supplementary oxygen (\%) and route of nutritional support were recorded.

\subsection{Measurement of resting energy expenditure (REE)}

Indirect calorimetry (IC), a measure of minute-by-minute carbon dioxide production $\left(\mathrm{VCO}_{2}\right)$ and oxygen consumption $\left(\mathrm{VO}_{2}\right)$, via an open ventilated hood system was used to measure REE. A Deltatrac II (Datex-Ohmeda, Helsinki, Finland) portable IC was used with all patients. The gas analysers within the Deltatrac were calibrated using Quickcal with the concentration of 95\% oxygen, 5\% carbon dioxide (Datex-Ohmeda, Helsinki, Finland) prior to each measurement. A flow calibration to assess the overall performance of the system was carried out every 6 months. A standard protocol was used by the investigator when operating the IC.

If the patient required supplementary oxygen, a supplementary oxygen kit (Datex-Ohmeda, Helsinki, Finland) was attached to the Deltatrac II. The supplementary oxygen was allowed to flow through the system for approximately $20 \mathrm{~min}$ prior to the measurement time. A ventilated hood was placed over the patient's head and neck. For those patients requiring supplementary oxygen, an elastic seal was attached to the canopy to ensure there were no leaks around the tracheostomy site. The respiratory gases were collected up to $60 \mathrm{~min}$. Steady state (SS) conditions were defined as five, four or three consecutive minutes of data where the coefficient of variation (CV) was $\leq 10 \%$ for $\mathrm{VCO}_{2}$ and $\mathrm{VO}_{2}$ values, $\leq 5 \%$ for $\mathrm{RQ}$ and the $\mathrm{RQ}$ value was in the physiologic range of 0.67-1.3. The patient's oxygen saturation levels were continually monitored during the measurement time using an oxygen pulsimeter (Welch-Allyn 52000 series, Welch-Allyn, USA). Minute-by-minute measurements of $\mathrm{VCO}_{2}(\mathrm{ml} /$ $\mathrm{min}), \mathrm{VO}_{2}(\mathrm{ml} / \mathrm{min}), \mathrm{RQ}\left(\mathrm{VCO}_{2} / \mathrm{VO}_{2}\right)$ and $\mathrm{FiO}_{2}$ (\%) were downloaded to a COLLECT software programme (Datex-Engstrom Division, Helsinki, Finland) when the measurement time had ended.

Measured REE (MREE (kcal/day) was calculated using the abbreviated Weir equation. ${ }^{11}$

$\mathrm{REE}=\left(\left(\mathrm{VO}_{2}(3.941)+\mathrm{VCO}_{2}(1.106)\right) \times 1.44\right.$

$\mathrm{VCO}_{2}$ and $\mathrm{VO}_{2}$ were measured in millilitres $(\mathrm{ml})$ per minute and REE measured in kilocalories per day.

\subsection{Prediction equations}

The prediction equations used to estimate REE in all subjects are shown in Table 1 . These were the most widely used equations of Harris-Benedict and FAO/WHO/UNU. These regression equations use simple variables of age, gender, weight and/or height to estimate REE as shown in Table $1^{12-13}$

\subsection{Statistical analysis}

Statistical analysis was conducted using the SPSS for windows version 12.0.1 (SPSS, Chicago, IL, USA). Normally distributed continuous variables are described as mean \pm SD unless otherwise

Table 1

Equations used to predict REE in clinical practice.

\begin{tabular}{ll}
\hline Author(s) & Equation for REE $(\mathrm{kcal} /$ day $)$ \\
\hline Harris-Benedict $(\mathrm{HB})^{12}$ & Men $=66+13.75(\mathrm{wt})+5.0(\mathrm{ht})-6.76($ age $)$ \\
& Women $=665+9.56(\mathrm{wt})+1.85(\mathrm{ht})-4.68($ age $)$ \\
FAO/WHO/UNU & \\
Age $18-29$ years & Men $=15.1(\mathrm{wt})+692:$ women $=14.8(\mathrm{wt})+487$ \\
Age $30-59$ years & Men $=11.5(\mathrm{wt})+873:$ women $=8.3(\mathrm{wt})+846$ \\
Age $60-74$ years & Men $=11.9(\mathrm{wt})+700:$ women $=9.2(\mathrm{wt})+687$ \\
\hline
\end{tabular}

Wt, weight $(\mathrm{kg})$; ht, height $(\mathrm{cm})$ 
stated. A $p$ value of $<0.05$ was considered statistically significant. Descriptive statistics were used to describe the subject population. Each patient's serial measurements were summarised using the area under the curve. A student's $t$-test was used to assess agreement between mean predictive values and mean measured REE. The Bland-Altman method was used to assess agreement between the standardised areas of measured values and predicted values. Multiple weighted regression analyses were used to evaluate the relationship between the explanatory variables and measured REE in the study sample.

\section{Results}

\subsection{Patient demographics}

A total of 210 repeated IC measurements were recorded for 45 patients recruited into the study. Of these measurements 43 (20.5\%) were unsuccessful resulting in 167 successful IC measurements. Of the 45 patients recruited into the study, three patients failed to yield any successful measurements. Therefore the subsequent analysis was based on data from 42 patients. The patient characteristics are shown in Table 2.

All 42 patients had a serious traumatic brain injury with a mean admission GCS score of 6.2 (range 3-11) and were not receiving artificial ventilation or sedation upon inclusion into the study. The cause of TBI in our patient population was as a result of: falls $(n=22)$; road traffic accidents $(n=13)$; assaults $(n=4)$; quad bicycle accidents $(n=2)$; and gunshot wounds $(n=2)$. Sixty-nine percent $(n=29)$ of our patient population underwent neurosurgery. All patients spent variable lengths of time in the Regional Intensive Care Unit (RICU) at the RVH prior to transfer to the Regional Neurosurgical Unit (RNU). The mean length of time from injury to the first metabolic measurement was 21 days (range 5-67 days).

Using the World Health Organization (WHO) classification of BMI $\left(\mathrm{kg} / \mathrm{m}^{2}\right), 29 \%$ of our study population were considered underweight (BMI $<18.5$ ), 58\% were considered normal weight (BMI 18.5-24.99), 9.6\% were considered overweight (BMI 25-29.99), and $3 \%$ were considered clinically obese (BMI $>30)$. Forty patients in the study sample had repeated weight measurements. Eighty-five percent of these patients experienced weight loss $(n=34)$ within the study time. The mean weight loss was $2 \mathrm{~kg}$ (range 0.1-10 kg; SD 2.13) over a mean 5.5 days (range 1-11 days; SD 2.7). The majority of patients at the time of measurement required enteral nutrition support: 58\% required nasogastric feeding; $4 \%$ required

Table 2

Patient characteristics of 42 patients with a serious traumatic brain injury.

\begin{tabular}{ll}
\hline Patient characteristic $(n=42)$ & Mean $(\mathrm{SD})$ range \\
\hline Age (years) & $35.6(14.6) 17-65$ \\
Male/female & $28 / 14$ \\
Admission GCS & $6.2(2.4) 3-11$ \\
Measurement GCS & $11(2.85) 4-15$ \\
Time since injury (days) & $21.1(11.6) 5-67$ \\
Weight $(\mathrm{kg})$ & $61.9(14.0) 36.5-127$ \\
Height $(\mathrm{cm})$ & $170.5(10.3) 152-190$ \\
Body mass index $\left(\mathrm{kg} / \mathrm{m}^{2}\right)$ & $21.2(3.7) 15.0-35.9$ \\
Body temperature $\left({ }^{\circ} \mathrm{C}\right)$ & $36.8(0.6) 35.5-38.8$ \\
Measured REE $(\mathrm{kcal} / \mathrm{day})$ & $1588(445.6) 910-4364$ \\
$\mathrm{FAO}^{2} \mathrm{WHO} / \mathrm{UNU} \mathrm{REE}(\mathrm{kcal} / \mathrm{day})$ & $1512(237.4) 1024-2610$ \\
$\mathrm{HB} \mathrm{REE}(\mathrm{kcal} / \mathrm{day})$ & $1497(234.8) 1012-2570$ \\
$\mathrm{VCO}_{2}(\mathrm{ml} / \mathrm{min})$ & $191(48) 119-479$ \\
$\mathrm{VO}_{2}(\mathrm{ml} / \mathrm{min})$ & $225(62.9) 127-634$ \\
$\mathrm{RQ}$ & $0.86(0.10) 0.69-1.19$ \\
\hline
\end{tabular}

GCS, Glasgow comma score; $\mathrm{VCO}_{2}$, carbon dioxide production; $\mathrm{VO}_{2}$, oxygen consumption; $\mathrm{RQ}$, respiratory quotient. supplementary nasogastric feeding in addition to oral diet; $3 \%$ received nutrition support via a percutaneous endoscopic gastrostomy (PEG) tube; oral diet was consumed by $34 \%$ of our patient group whilst $1 \%$ was nil orally without feeding access. A 4 -h fast, prior to the measurement time, was observed for all patients included in the study. The mean prescribed kilocalorie intake for patients requiring enteral nutrition support was $2295 \mathrm{kcal} / \mathrm{day}$.

Each of the 42 patients had a mean of four successful metabolic measurements (range 1-9) at variable lengths of time after the initial injury. Mean GCS at the time of measurement was 11 (range 4-15). Approximately $53 \%$ of our patient group required supplementary oxygen via percutaneous tracheostomy to maintain oxygen saturations. Therefore a strict IC measurement protocol as described in Section 2 was observed for these patients. Oxygen saturations in addition to concentration of inspired oxygen $\left(\mathrm{FiO}_{2}\right)$ were continually monitored throughout the measurement time by a trained investigator. Furthermore, only data meeting predefined SS conditions was used for data analysis. SS conditions were met in all successful measurements with a mean RQ value of 0.86 . Of the 167 successful measurements, 133 (80\%) achieved 5-min SS conditions, 18 (11\%) achieved 4-min SS conditions and $16(9 \%)$ achieved 3-min SS conditions. Twenty percent of all metabolic measurements recorded were unsuccessful.

\subsection{Agreement between measured REE and predictive values ( $k c a l / d a y)$}

Mean measured REE was 1588 kcal/day (SD 446 kcal/day). Fig. 1 illustrates the serial mean measured REE over time (days since injury) for each of the 42 patients with successful IC measurements. However, in order to compare the measured REE with the FAO/ WHO/UNU and HB prediction values at a group and individual level it was necessary to summarise serial sets of repeated measurements for individual patients since each patient had varying time intervals between measurements of REE. Each patient set was summarized by its standardized area under the line graph of measurement against time (days). Area under the curve (AUC) is a standard method of summarizing serial observations; this area was divided by the time interval in days from the first measurement to the final measurement to give the standardized area (kcal/ day). The mean within patient CV was calculated for 42 patients with two or more measurements as $11 \%$ (SD 8.2; range $0-43 \%$ ). The analyses of the AUC data were based on 40 patients; two patients with measured REE CV values exceeding $30 \%$ were excluded (the results were considered to be unreliable). The mean within patient CV was $10 \%$ (SD 5.6; range 0-21\%) when the two patients with CV exceeding $30 \%$ were excluded.

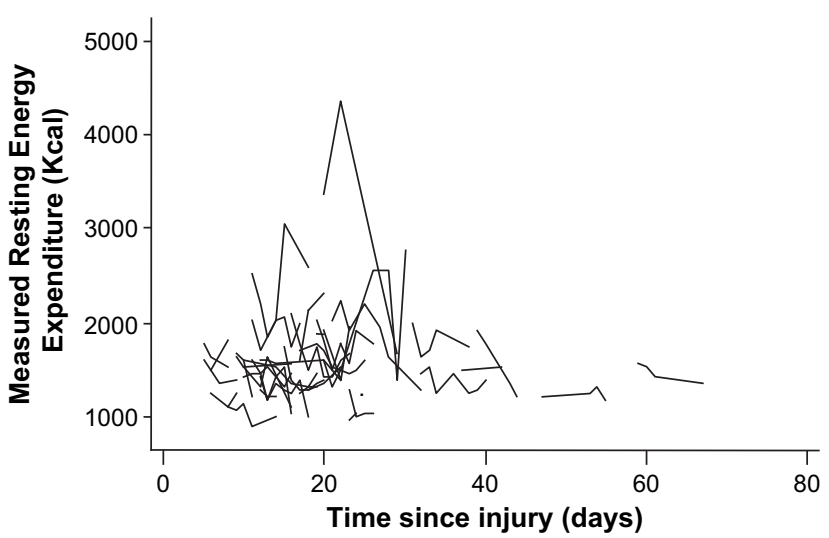

Fig. 1. Individual plots of mean measured REE (kcal/day) over time (days since injury) for 42 patients recovering from serious TBI. 
Using a paired students $t$-test, there were no significant differences at a group level between the standardized areas for measured REE and predicted FAO/WHO/UNU values $(p=0.84)$; the standardized areas for measured REE values and the standardized areas for predicted $\mathrm{HB}$ values $(p=0.97)$ and the $\mathrm{FAO} / \mathrm{WHO} / \mathrm{UNU}$ prediction values and HB prediction values $(p=0.44)$.

To assess agreement at an individual level the Bland-Altman method was used. This method involves plotting the differences of the standardized areas for measured REE and is based on the predicted values for each patient against the average of these areas for each patient. The limits of agreement were defined as the mean difference \pm 2 SD of the mean differences between the measured REE and each of the prediction equations. The mean standardized area measured REE was $1510 \mathrm{kcal} /$ day (SD $308 \mathrm{kcal} /$ day). This is approximately $5 \%$ different from the calculated mean measured REE. However, it was necessary to use the standardized value for statistical analysis due to the variability in measured REE over variable periods of time for each individual patient. The level of agreement at $\pm 10 \%$ of the mean measured area REE was used to explore clinically acceptable limits of agreement between the measured REE values and the predicted values.

Bland-Altman plots (Figs. 2 and 3) for both predictive equations and measured REE indicate good agreement at the mean difference \pm 2 SD of the differences limits of agreement. Approximately $95 \%$ of predictive values were within these limits of agreement for the $\mathrm{FAO} / \mathrm{WHO} / \mathrm{UNU}$ equation and $97.5 \%$ for the $\mathrm{HB}$ equation. However, these limits of agreement were very wide in both directions, greater than $\pm 550 \mathrm{kcal} / \mathrm{day}$, which was considered not to be clinically acceptable. Hence, limits of agreement were also considered at the $\pm 10 \%$ of mean measured REE ( $\pm 151 \mathrm{kcal} /$ day). Both equations indicated poor agreement with measured REE at this level. The FAO/WHO/UNU prediction demonstrated $50 \%$ agreement at the $\pm 10 \%$ limit of agreement with approximately $22.5 \%$ differences greater than $10 \%$ of the mean measured REE and $27.5 \%$ of differences below $10 \%$ of the mean measured REE values. The HB produced similar results with $45 \%$ of predicted values within $\pm 10 \%$ of measured REE with $30 \%$ of differences greater than $10 \%$ and $25 \%$ of differences less than $10 \%$ of mean measured REE.

\subsection{Regression analyses}

The purpose of these analyses is to investigate the relationships between measured REE measurements and clinically obtained variables including GCS, patient status during the measurement of REE (whether the patient was awake (eyes open) or asleep (eyes closed), age (years), time since injury (days), gender, supplementary oxygen concentration $(\%)$, temperature $\left({ }^{\circ} \mathrm{C}\right)$, antibiotic treatment, weight $(\mathrm{kg})$, height $(\mathrm{cm})$ and $\mathrm{BMI}\left(\mathrm{kg} / \mathrm{m}^{2}\right)$.

The data consists of 167 records of the measurements/observations of the above variables from 42 patients; there was complete information on the above variables. Repeated measurements of a patient cannot be considered independent and as such should be analysed in an appropriate manner. Instead of analysing at the patient level, the unit of analysis is the "state" of a patient defined by the pair (GCS, patient status, i.e. awake or asleep) - from initial analysis it was found that these two variables have a significant effect on measured REE. This means that a patient may provide data for several states, e.g. patient 2 has two records for state (GCS 9, awake) and two records for state (GCS 10, awake). Where a patient has several records for a given state, the data in these records are averaged to give a mean record with weight equal to the number of records averaged. The frequencies of the numbers of records per state are shown in Table 3, e.g. 64 states had a single record, 26 states had two records, etc.

This process gave a set of 105 mean records which were analysed using weighted multiple regression modelling with the weights as described above, the dependent variable being

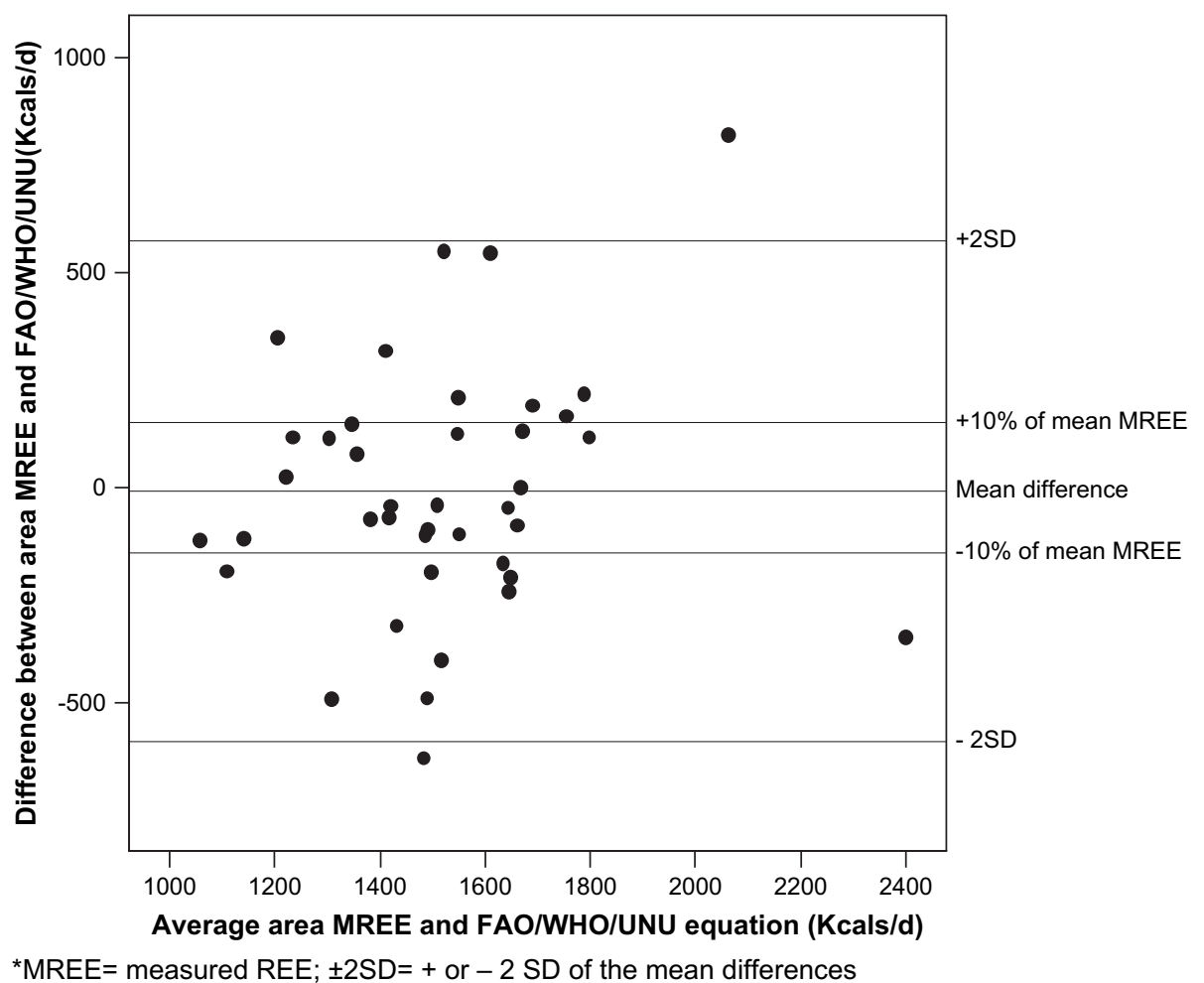

Fig. 2. Bland-Altman plot showing agreement between the standardized areas of measured REE and FAO/WHO/UNU predicted REE (kcal/day) in 40 patients with serious TBI. 


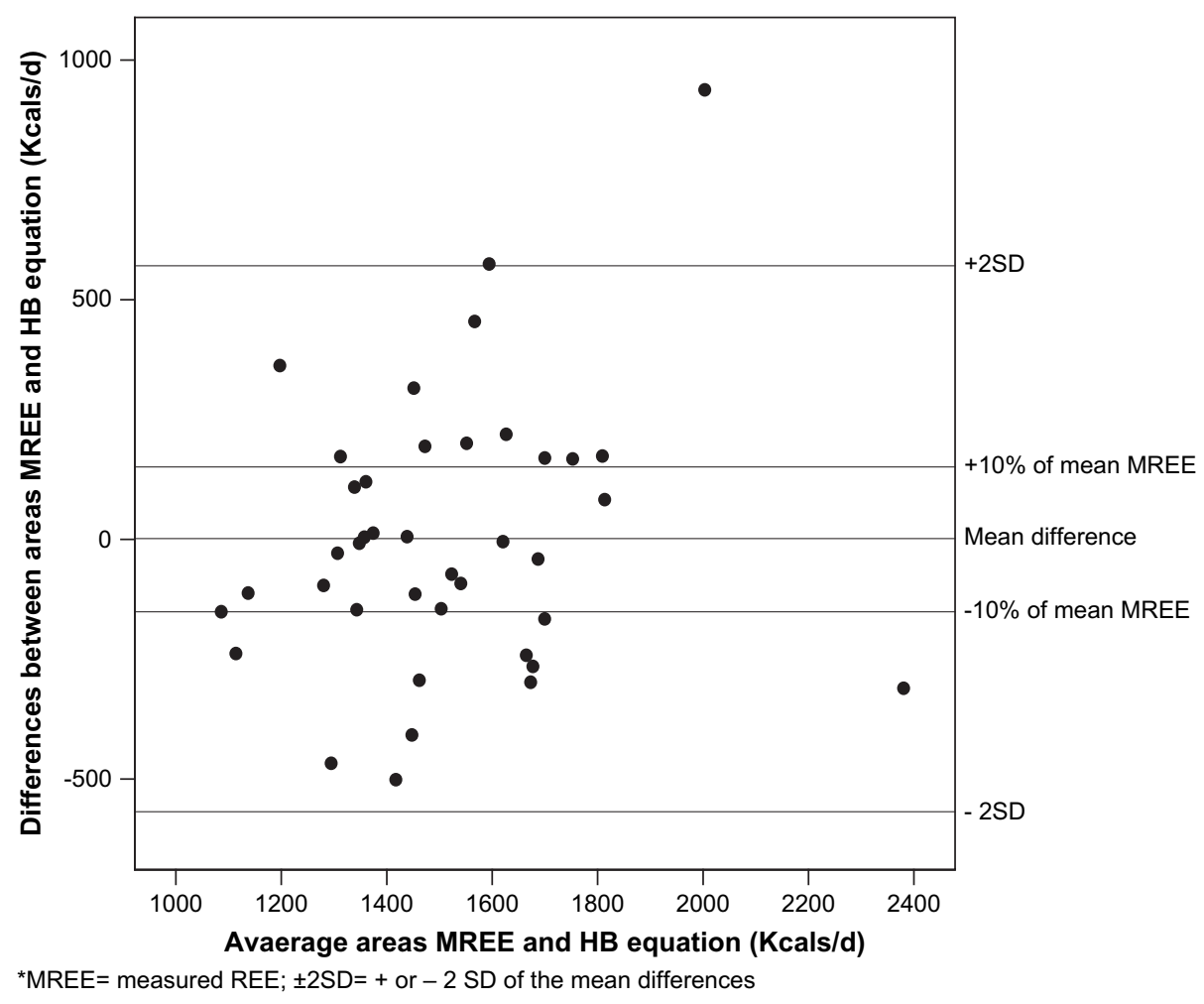

Fig. 3. Bland-Altman plot showing agreement between the standardized areas of measured REE and HB predicted REE (kcal/day) in 40 patients with serious TBI.

measured REE, the explanatory variables being the remaining variables listed above.

In the regression model with explanatory variables GCS and patient status and their interaction, the interaction is non-significant at the 5\% level ( $p=0.23)$ and therefore was not included in the subsequent models.

In the basic regression model, with explanatory variables GCS and patient status, both GCS $(p<0.001)$ and patient status $(p<0.001)$ had very highly significant effects on measured REE $\left(R^{2}\right.$ 0.25 ). Estimated mean measured REE decreased by $59 \mathrm{kcal}$ for a one unit increase in GCS, independently of patient status. Estimated mean measured REE for patient status when awake is $319 \mathrm{kcal}$ greater than estimated mean measured REE for patient status when asleep, independently of GCS. All subsequent models will contain GCS and patient status.

Regression models including GCS, patient status and each of the remaining variables were fitted. Age $(p=0.61)$, time since injury $(p=0.58)$, supplementary oxygen concentration $(p=0.28)$ and antibiotic treatment $(p=0.69)$ were found to be non-significant predictors of measured REE and were not included in subsequent models. Each of the other explanatory variables was found to have a significant effect on measured REE. Using a cut off value of 0.2 for the $p$ values, the following explanatory variables were considered

\section{Table 3}

Frequencies of the numbers of records per patient state defined by GCS and patient status during 167 IC measurements in 42 patients with TBI.

\begin{tabular}{lc}
\hline Number of records per state & Frequency \\
\hline 1 & 64 \\
2 & 26 \\
3 & 10 \\
4 & 4 \\
5 & 1 \\
Total & 105 \\
\hline
\end{tabular}

in the multivariable regression modelling: GCS; patient status; BMI; gender; temperature; weight; and height.

Variable selection by backward elimination removed gender $(p=0.87)$ and weight $(p=0.84)$ to give the model:

GCS $\mathrm{B}=-51(p<0.001)$; patient status $\mathrm{B}=330(p<0.001)$; temperature $\mathrm{B}=141(p=0.014)$; $\mathrm{BMI} \mathrm{B}=40(p<0.001)$; height $\mathrm{B}=11(p=0.001) . R^{2}=48 \%$.

A further similar model is presented where variable selection by backward elimination removed gender $(p=0.94)$ and BMI $(p=0.98)$ from the multivariable model to give the model shown in Table 4. This was the preferred model as fewer clinically obtained variables are required for the estimation of REE (kcal/ day) in clinical practice. This model shows that estimated mean measured REE decreases by $50 \mathrm{kcal}$ for a one unit increase in GCS independent of the other variables. Mean measured REE is $330 \mathrm{kcal}$ greater when the patient status is recorded as awake rather than asleep when adjusted for the effects of the other variables. Similarly, there is a $144 \mathrm{kcal}$ increase in estimated mean measured REE for a $1{ }^{\circ} \mathrm{C}$ increase in temperature and an increase of $14 \mathrm{kcal}$ for a $1 \mathrm{~kg}$ increase in weight when adjusted for the effects of other variables. This final model gives an $R^{2}$ value of $47 \%$.

\section{Table 4}

Multivariable regression analysis showing the effect of significant explanatory variables on measured REE measurements in patients with a TBI.

\begin{tabular}{lcccc}
\hline Variable & Coefficient B & $p$ value & \multicolumn{2}{c}{ 95\% Confidence interval for B } \\
\cline { 4 - 5 } & & & Lower bound & Upper bound \\
\hline Constant & -4166 & 0.05 & -8414 & 81 \\
GCS & -50 & $<0.0001$ & -73 & -28 \\
Patient status & 330 & $<0.0001$ & 204 & 466 \\
Temperature & 144 & 0.013 & 31 & 256 \\
Weight & 14 & $<0.0001$ & 10 & 19 \\
\hline
\end{tabular}




\subsection{Final model}

Measured REE (kcal/day) $=-4166-50 \mathrm{GCS}+330$ patient status (1,eyes open; 0,eyes closed) +144 temperature $\left({ }^{\circ} \mathrm{C}\right)+14$ weight $(\mathrm{kg})$

\section{Discussion}

The HB equations and/or FAO/WHO/UNU equations are applied to both healthy populations and clinical populations worldwide to estimate basal energy requirements. The limitations of these equations are frequently unrecognized and they are often applied injudiciously at the individual level for both patients and healthy volunteers. Other authors have questioned the accuracy of the both the $\mathrm{HB}$ and $\mathrm{FAO} / \mathrm{WHO} / \mathrm{UNU}$ equations in healthy, obese and clinical populations. ${ }^{14-16}$ Our results in patients recovering from brain trauma add to the growing weight of scientific research questioning the validity of these prediction equations. We found that the HB and $\mathrm{FAO} / \mathrm{WHO} / \mathrm{UNU}$ equations correctly predicted resting energy requirements within $10 \%$ of the measured values in approximately $50 \%$ of cases. Previous studies evaluating predicted values and measured REE in various clinical populations have used a limit of agreement at $\pm 10 \%$ of the mean measured REE. It has been assumed in the literature that hypermetabolism in clinical populations is defined as $10 \%$ or more above predicted REE and hypometabolism as $10 \%$ or more below predicted REE. ${ }^{17}$ Interestingly, approximately $25 \%$ of measured values in our patient group demonstrated a hypermetabolic state whereas $25 \%$ demonstrated a hypometabolic state. These results are consistent with measured REE in other clinical populations such as surgical patients and critically ill patients. ${ }^{17-19}$ Data from critically ill patients have shown that approximately 35-65\% demonstrate a classic hypermetabolic response, $30-50 \%$ showing a normometabolic pattern and a further 15-20\% having a hypometabolic response. ${ }^{19}$ The significance of a hypometabolic response in critically ill patients is not clear. However, in other clinical groups at some point the hypermetabolic response to trauma subsides as the patient recovers. Weight loss and malnutrition per se can reduce REE by up to $40 \%{ }^{20-22}$ In our study, $29 \%$ of the study group were initially clinically underweight with $85 \%$ of patients experiencing further weight loss during the study period. This may have contributed to the variability in measured REE in our study sample.

Until now, little data existed regarding REE in patients greater than 2 weeks post severe brain injury. Studies to date have produced conflicting results in only small numbers of brain injured patients. ${ }^{3,23}$ Additionally, the majority of research investigating REE in brain injured patients was conducted $10-20$ years ago. There have been advances in medical, surgical and rehabilitation treatment since this time which may influence REE measurements. We have reported our results in a significantly larger group of seriously brain injured patients who are representative of the normal clinical population. The results indicate that REE is highly variable in patients recovering from TBI. The mean within patient variability was recorded as $11 \%$ (range $0-43 \%$ ) which is similar to recorded variability in measured REE in other clinical populations such as critically ill patients. ${ }^{19,21,22}$ This is in contrast to healthy individuals where the reported normal day-to-day variation of measured REE is approximately $3-6 \%{ }^{22,24-25}$

The demonstrated differences between the measured and predicted values in our patients recovering from TBI are multifactorial and include the effects of measurement error, investigative error and biological variation. We minimised measurement error by employing an evidence-based standardised protocol for the operation of the metabolic monitor, using one trained investigator to perform all metabolic measurements and rigorously analysing the data using predetermined steady state criteria for analysis. Hence, over $20 \%(n=43)$ of metabolic measurements in this study were unsuccessful. It would have been impossible to conduct IC measurements for longer than $60 \mathrm{~min}$ in this patient group due to the unstable nature of the clinical condition, frequent need for therapy intervention, medical support and investigations over a 24-h period. Despite our efforts to minimise measurement error, there are accuracy and precision errors associated with the IC calorimeter and procedure which have been reported as less than $5 \%$, when the same calorimeter is used. ${ }^{25,26}$

Biological variation in REE during the first 2 weeks of brain injury have been attributed to the effects of sedation, barbiturate therapy, steroid treatment, mechanical ventilation, diet induced thermogenesis, days since injury, severity of injury, body temperature, abnormal motor activity and/or infection, which can independently serve to increase or decrease measured REE. ${ }^{3-9,21,22}$

To our knowledge, this is the first study investigating factors contributing to measured REE in a larger group of patients recovering from TBI when sedation and ventilation have been discontinued. We demonstrated that the severity of brain injury continues to affect the energy expenditure of patients in the later stages of trauma recovery. We also showed that REE is significantly higher when the metabolic measurement is performed in brain injured patients when eyes were noted to be open during the steady state. This is probably related to the stimulation of both the CNS and sympathetic nervous system with concomitant increase in muscle tone. Wakefulness has been described as a complex process with not only stimulation of CNS activity but increased autonomic activity and sympathetic nervous system activity with release of catecholamines from the adrenal medulla. ${ }^{27}$ In clinically stable hospitalized patients and critically ill mechanically ventilated patients these factors have resulted in a $10 \%$ increase in energy expenditure. ${ }^{21,22}$ Wakefulness resulted in a mean $22 \%$ increase in energy expenditure in our patient sample. One possible explanation for the differences in the results obtained is the direct effect of the brain injury itself on the regulation of the complex processes governing wakefulness. There is some evidence that arousal changes in the damaged brain are altered, suggesting control mechanisms have been lost or damaged, compared with the normal brain. ${ }^{27}$ Additionally, hypocretin-1, involved in the regulation of the sleep-wake cycle, was found to be abnormally low in $95 \%$ of 44 patients with acute TBI suggesting some degree of hypothalamic damage. ${ }^{28}$ Body temperature was also a significant contributor, but not the main determinant, of the overall variability in measured REE in our study sample. We found an average $9.5 \%$ increase in REE for each measured degree centigrade rise in temperature. This agrees with previous research in other clinical groups where REE increased by $6-13 \%$ for each degree centigrade rise in temperature. ${ }^{22,29}$

Body size is one of the biggest determinants of REE in humans. We found that body weight was a significant contributor to the overall variability in measured REE in our study sample. This is unsurprising since the majority of prediction equations used today to estimate REE in clinical populations include body weight as a variable. Body weight alone explained up to $75 \%$ of the variance in REE in the original HB regression equations. ${ }^{30}$ However, we found that body weight alone explained only $19 \%$ of the variation in measured REE in our study sample. The ability of the multiple variables (GCS, patient status (eyes open or eyes closed), temperature and weight) to estimate REE in spontaneously breathing, nonsedated patients in the latter stages of serious TBI was only fair. Over $50 \%$ of the variance in measured REE remains unaccounted for. Clearly, there are factors not identified in our study that will determine REE in this patient group. Further study of body composition and fat free mass, hormonal status, sympathetic 
nervous system activity, the effects of hypertonicity and posturing and putative autonomic dysregulation may yield additional information regarding the variation in measured REE in this patient group. Furthermore, to facilitate the provision of adequate nutritional support to patients recovering from TBI, knowledge of total energy needs is important. The overall effect of physical activity and dietary induced thermogenesis on total energy needs in patients recovering from TBI is uncertain. Further research is warranted using high quality tracer techniques, such as bicarbonate-urea or doubly labelled water in combination with indirect calorimetry, to investigate the extent of total energy requirements in this complex group.

\section{Conclusion}

Due to the variable nature of measured REE in patients recovering from brain injury reliance on currently available prediction equations can lead to serious errors in the calculation of REE. Currently, it may be necessary to measure individual REE using the technique of IC in clinical practice, to help guide the provision of adequate nutritional support.

\section{Conflicts of interest}

There are no conflicts of interest to declare.

\section{Acknowledgements}

All named authors made significant contributions to the study design, recruiting of patients, data collection, data analysis and preparation of the manuscript for submission. This research was supported by a grant from the Research \& Development Office, Northern Ireland. This research was conducted using funding from the Research \& Development Office, Northern Ireland. Reprints will be available from the authors.

\section{References}

1. Perel P, Yanagawa T, Bunn F, Roberts IG, Wentz R. Nutritional support for headinjured patients. Cochrane Database of Syst Rev. 2006;(4):CD001530. doi:10.1002/14651858.CD001530.

2. Härtl R, Gerber LM, Quanhong NI, Ghajar J. Effect of early nutrition on deaths due to severe traumatic brain injury. J Neurosurg 2008;109:50-6.

3. Bruder N, Dumont JC, Francois G. Evolution of energy expenditure and nitrogen excretion in severe head-injured patients. Crit Care Med 1991;19:43-8.

4. Clifton GL, Robertson CS, Sung CC. Assessment of nutritional requirements of head-injured patients. J Neurosurg 1986;64:895-901.

5. Wilson RF, Tyburski JG. Metabolic responses and nutritional therapy in patients with severe head injuries. J Head Trauma Rehabil 1998;13:11-27.

6. Deutschman CS, Konstantinides FN, Raup S, Cerra FB. Physiological and metabolic response to isolated closed-head injury. Part 2: Effects of steroids on metabolism. Potentiation of protein wasting and abnormalities of substrate utilization. J Neurosurg 1987;66:388-95.

7. Dempsey DT, Guenter P, Mullen JL, Fairman R, Crosby LO, Spielman G, et al Energy expenditure in acute trauma to the head with and without barbiturate therapy. Surg Gynecol Obstet 1985;160:128-34.

8. Bruder N, Lassegue D, Pelissier D, Graziani N, Francois G. Energy expenditure and withdrawal of sedation in severe head-injured patients. Crit Care Med 1994;22:1114-9.

9. Brain Trauma Foundation. Guidelines for the management of severe traumatic brain injury. 3rd ed. Nutrition. J Neurotrauma 2007;24(Suppl. 1):S77-82.

10. Bland JM, Altman DG. Statistical methods for assessing agreement between two methods of clinical measurement. Lancet 1986;1(8476):307-10.

11. Weir JB. New methods for calculating metabolic rate with special reference to protein metabolism. J Physiol 1949;109:1-9.

12. Harris JA, Benedict FG. A biometric study of basal metabolism in man. Washington DC, USA: Carnegie Institution of Washington; 1919. [Publication no. 279.].

13. Schofield WN. Predicting basal metabolic rate, new standards and review of previous work. Human Nutr Clin Nutr 1985;39:5-41.

14. Owen OE. Resting metabolic requirements of men and women. Mayo Clin Proc 1988;63:503-10

15. Miles JM. Energy expenditure in hospitalized patients: implications for nutritional support. Mayo Clin Proc 2006;81:809-16.

16. Frankenfield DC, Rowe WA, Smith JS, Cooney RN. Validation of several established equations for resting metabolic rate in obese and nonobese people. $\mathrm{J} \mathrm{Am}$ Diet Assoc 2003;103:1152-9.

17. McClave SA, Snider HL. Understanding the metabolic response to critical illness: factors that cause patients to deviate from the expected pattern of hypermetabolism. New Horizons 1994;2:139-46.

18. da Rocha EE, Alves VG, Silva MH, Chiesa CA, da Fonseca RB. Can measured resting energy expenditure be estimated by formulae in daily clinical nutrition practice? Curr Opin Clin Nutr Metab Care 2005;8:319-28.

19. Weissman C, Kemper M, Askanazi J, Hyman AI, Kinney JM. Resting metabolic rate of the critically ill patient: measured versus predicted. Anesthesiology 1986;64:673-9.

20. Cunningham JJ. Resting energy expenditure in malnutrition. Am J Clin Nut 1985:41:371-2.

21. McClave SA, McClain CJ, Snider HL. Should indirect calorimetry be used as part of nutritional assessment? J Clin Gastroenterol 2001;33:14-9.

22. McClave SA, Snider HL. Use of indirect calorimetry in clinical nutrition. Nutr Clin Pract 1992;7:207-21.

23. Weekes E, Elia M. Observations on the patterns of 24-hour energy expenditure changes in body composition and gastric emptying in head-injured patients receiving nasogastric tube feeding. J Parenter Enteral Nutr 1996;20:31-7.

24. Garby L, Lammert O. Within-subjects between-days-and-weeks variation in energy expenditure at rest. Human Nutr Clin Nutr 1984;38:395-7.

25. Bader N, Bosy-Westphal A, Dilba B, Muller MJ. Intra- and interindividual variability of resting energy expenditure in healthy male subjects - biological and methodological variability of resting energy expenditure. $\mathrm{Br} J \mathrm{Nutr}$ 2005;94:843-9.

26. Elia M, Stratton R, Stubbs J. Techniques for the study of energy balance in man Proc Nutr Soc 2003;62:529-37.

27. Evans BM. What does brain damage tell us about the mechanisms of sleep? J R Soc Med 2002;95:591-7.

28. Baumann CR, Stocker R, Imhof HG, Trentz O, Hersberger M, Mignot E, et al Hypocretin-1 (orexin A) deficiency in acute traumatic brain injury. Neurology 2005;65:147-9.

29. Dubois EF, editor. Fever and regulation of body temperature. Springfield, IL, USA Charles C Thomas; 1948.

30. Frankenfield DC, Muth ER, Rowe WA. The Harris-Benedict studies of human basal metabolism: history and limitations. J Am Diet Assoc 1998;98:439-45. 